\title{
Preparation of polydivinylbenzene/natural rubber capsule encapsulating octadecane: Influence of natural rubber molecular weight and content
}

\author{
A. Chaiyasat, C. Waree, K. Songkhamrod, P. Sirithip, V. Voranuch, P. Chaiyasat ${ }^{*}$ \\ Department of Chemistry, Faculty of Science and Technology, Rajamangala University of Technology Thanyaburi, \\ Klong 6, Thanyaburi, 12110 Pathumthani, Thailand
}

Received 2 June 2011; accepted in revised form 4 August 2011

\begin{abstract}
The encapsulation of octadecane (OD) as heat storage material was studied. The core-shell polydivinylbenzene (PDVB)/natural rubber (NR) capsules encapsulating OD was prepared using the Self-assembling of Phase Separated Polymer (SaPSeP) method by suspension polymerization. The mixture of dispersed phase consisting of DVB, NR, OD and benzoyl peroxide was added in polyvinyl alcohol aqueous solution and then homogenized at 5,000 rpm for 5 minutes. The obtained monomer droplet emulsion was subsequently polymerized at $80^{\circ} \mathrm{C}$ for 8 hours resulting in PDVB/NR capsule encapsulating OD. The influence of molecular weight and content of NR on the encapsulation efficiency and thermal properties of the encapsulated OD were investigated. It was found that both factors affected on the preparation of PDVB/ NR/OD capsule. High molecular weight NR restricted phase separation of formed PDVB. High NR content also reduced phase separation of PDVB due to the increase of internal viscosity. Then, only the incorporation of appropriate molecular weight and content of NR resulted in the formation of PDVB/NR/OD capsule.
\end{abstract}

Keywords: thermal properties, encapsulation, heat storage materials, natural rubber

\section{Introduction}

In recent years, microcapsules of heat storage materials have attracted for many applications such as air condition of building, solar heat storage and thermally adaptable fibers [1-3]. Paraffin waxes such as tetradecane (TD), hexadecane (HD), octadecane (OD), nonadecane (ND), and eicosane are useful as one group of numerous heat storage materials that melt and solidify at a wide range of temperatures, making them attractive for many applications [4]. Several methods have been carried out to prepare heat storage microcapsules. The in situ polymerization to fabricate the microcapsules and nanocapsules containing OD core with melamine-formaldehyde shell [5], resorcinol-modified melamineformaldehyde shell [6] were reported. Three types of paraffin waxes (HD, OD and ND) were encapsulated through complex coacervation of natural and biodegradable polymers, gum arabic-gelatin mixture [7]. Polystyrene (PS) microcapsules containing paraffin wax were synthesized by suspension like polymerization [8]. The Self-assembling of Phase Separated Polymer (SaPSeP) method is one of many methods applied for the encapsulation of them [912]. The polymer chains formed during polymerization in the monomer droplet are diffused and trapped near the interface based on surface coagulation and gradually piled at the inner interface resulting in a polymer shell. After the completion of polymerization, heat storage material was encapsulated inside as the capsule core. Previously, we have prepared the microcapsule of polydivinylbenzene (PDVB) encap-

\footnotetext{
${ }^{*}$ Corresponding author, e-mail: p_chaiyasat@mail.rmutt.ac.th
} (c) BME-PT 
sulated OD (PDVB/OD) by microsuspension polymerization utilizing the SaPSeP method [13]. The prepared capsules are spherical with smooth outer surface.

Currently, there is a high level of interest in the utilization of natural polymers due to environmantal awareness. Natural rubber (NR) is one of the most important biopolymers in Thailand. NR latex is exuded from the Hevea brasiliensis tree as an aqueous emulsion [14]. It displays excellent elasticity and flexibility widely used in various applications such as medical gloves and tubing. Therefore, it is interesting to incorporate NR into PDVB shell. It not only improves the mechanical properties of PDVB shell but also reduces the utilization of petrochemical monomer corresponding with their costs.

In this study, the preparation of microcapsule encapsulating OD in polymer composite shell of PDVB and NR (PDVB/NR/OD) was carried out by suspension polymerization utilizing the SaPSeP method. The influence of the molecular weight of NR and its content on the encapsulation efficiency and thermal properties of encapsulated OD were investigated.

\section{Experimental}

\subsection{Materials}

DVB (Aldrich, Wisconsin, USA; purity, 80\%) was washed with $1 \mathrm{~N}$ sodium hydroxide (BDH Prolabo, Leuven, Belgium) and distilled water to remove polymerization inhibitors before use. NR (Thai Rubber Latex Co., Ltd., Bangkok, Thailand) was used as received and oxidized with aqueous hydrogen peroxide solution (QReC, Auckland, New Zealand; $30 \% \mathrm{v} / \mathrm{v}$ ) in the combination with sonication to reduce the molecular weight. Poly (vinyl alcohol) (PVA) (Aldrich, Wisconsin, USA; degree of saponification, 87-90\%) was used as received. Reagentgrade benzoyl peroxide (BPO) (Merck, Munich, Germany) was purified by recrystallization. OD (Aldrich, Wisconsin, USA; 99.5\%) was used as received. Tetrahydrofuran (THF) (QReC, Auckland, New Zealand; HPLC grade) was used as received.

\subsection{Microcapsules preparation}

The microcapsules of PDVB/NR/OD were prepared by suspension polymerization under the conditions listed in Table 1. The homogeneous organic phase of DVB/NR and OD at the ratio of $50: 50 \% \mathrm{wt} / \mathrm{wt}$ (approximately $10 \mathrm{wt} \%$ of aqueous solution) were mixed with BPO ( $8 \mathrm{wt} \%$ of monomer) and then added to the aqueous phase containing PVA (1.5 $\mathrm{g}$ of PVA in $150 \mathrm{~g}$ of water). Emulsification was carried out by homogenization at the speed of $5000 \mathrm{rpm}$ for 5 minutes resulting in the organic phase droplets dispersed in the aqueous medium. The resulting emulsions were subsequently transferred to the reactor and polymerized at $80^{\circ} \mathrm{C}$ for 8 hours with the stirring rate at $200 \mathrm{rpm}$ under $\mathrm{N}_{2}$ atmosphere.

\subsection{Characterizations}

Number- and weight-average molecular weights ( $M_{\mathrm{n}}$ and $M_{\mathrm{w}}$, respectively) and molecular weight distributions of NR and oxidized NR were determined using a gel permeation chromatograph (GPC) (Water 2414, Water, USA) with two poly(styrenedivinylbenzene) gel columns (Phenogel $5 \cdot 10^{3}$ and $5 \cdot 10^{5}$ A, $7.8 \mathrm{~mm}$ i.d $\times 30 \mathrm{~cm}$, Phenomenex, USA) connected in series. The flow rate of THF as eluent was maintained at $1.0 \mathrm{ml} / \mathrm{min}$ with column temperature of $40^{\circ} \mathrm{C}$ and elution was monitored with refractive index detector. The columns were calibrated with six standard PS samples $\left(2.5 \cdot 10^{3}-\right.$ $\left.6.0 \cdot 10^{5}, M_{\mathrm{w}} / M_{\mathrm{n}}=1.05-1.15\right)$.

The prepared capsules were observed with an optical microscope (OM) (SK-100EB \& SK-100ET, Seek, Thailand) and scanning electron microscope (SEM) (JSM-6510, JEOL, Japan) to investigate the inner structure and surface morphology of the microcapsules, respectively. The ultrathin cross sections of the capsules were observed with a transmission electron microscope (TEM) (JEM-1230, JEOL, Japan). Dried capsule particles were dispersed in epoxy matrix, cured at room temperature for $24 \mathrm{~h}$ and then microtomed.

The OD content in microcapsule was determined with thermogravimetric analyzer (TGA) (TGA 4000, Perkin-Elmer, USA) using heating rate of $5^{\circ} \mathrm{C} / \mathrm{min}$. The latent heats of crystallization $\left(H_{\mathrm{c}}\right)$ and melting $\left(H_{\mathrm{m}}\right)$ and the crystallization $\left(T_{\mathrm{c}}\right)$ and melting $\left(T_{\mathrm{m}}\right)$ temperatures of OD encapsulated in microcapsules in aqueous solution (solid content: ca 10\%) were measured with a differential scanning calorimeter (DSC) (DSC 4000, Perkin-Elmer, USA) under a $\mathrm{N}_{2}$ flow with the scanning temperature range and rate of $0-40^{\circ} \mathrm{C}$ and $5^{\circ} \mathrm{C} / \mathrm{min}$, respectively. To compare $H_{\mathrm{c}}$ and $H_{\mathrm{m}}$ of the encapsulated OD having different $\mathrm{wt} \%$ in the capsule particles and also bulk 
OD, the $H_{\mathrm{c}}$ and $H_{\mathrm{m}}$ values were used in the unit of joule per $1 \mathrm{~g}$ of encapsulated OD (J/g-OD). They were calculated from the cooling/heating peak area of DSC thermogram and OD content obtained from TGA analysis using the Equation (1):

$\mathrm{J} / \mathrm{g}-\mathrm{OD}=\frac{A}{B} \cdot 100$

where $A=H_{\mathrm{c}}$ or $H_{\mathrm{m}}$ of encapsulated OD in microcapsule dispersion obtained from DSC thermogram ( $\mathrm{J} / \mathrm{g}$-sample), $B=\% \mathrm{OD}$ in microcapsule dispersion obtained from TGA thermogram.

\section{Results and discussion}

The PDVB/NR/OD microcapsules prepared with various weight percents of NR $\left(M_{\mathrm{n}}=308130 \mathrm{~g} / \mathrm{mol}\right)$ were observed with OM compared with PDVB/OD capsules as shown in Figure 1. The PDVB/OD capsules (Figure 1a) were spherical and OD core was completely encapsulated with PDVB shell. When NR was added, phase separation was not observed

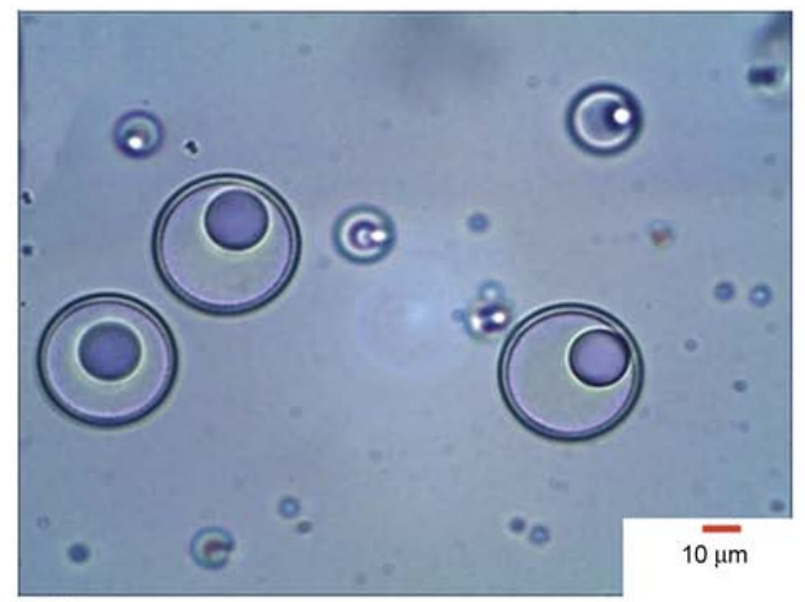

a)

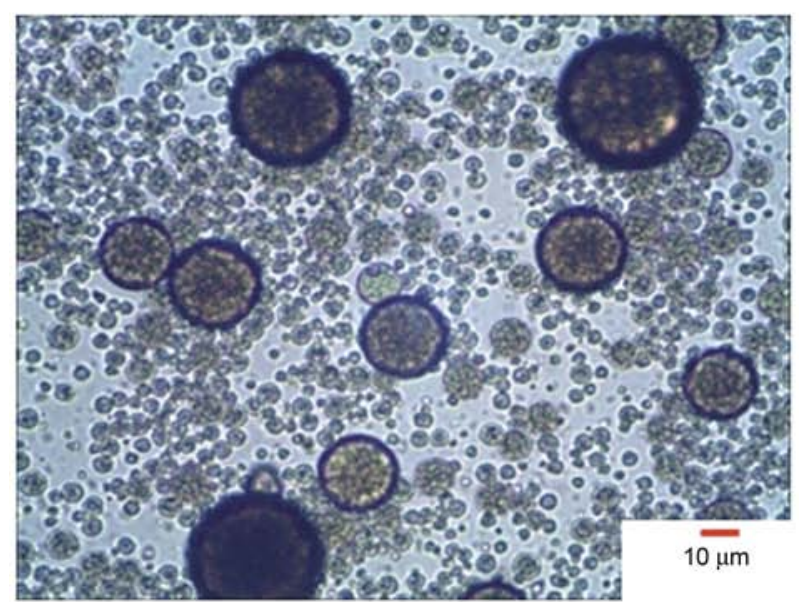

c)
Table 1. Recipes for the preparation of PDVB/NR capsules with encapsulated OD by suspension polymerization $^{\mathrm{a}}$ of DVB/NR/OD droplets prepared by homogenization $^{\mathrm{b}}$

\begin{tabular}{|c|c|c|c|c|}
\hline \multirow[b]{2}{*}{ Ingredient } & \multicolumn{4}{|c|}{ NR (wt\% of DVB) } \\
\hline & $\mathbf{0}$ & 1 & 2.5 & 5 \\
\hline DVB $\quad[\mathrm{g}]$ & 7.5 & 7.5 & 7.5 & 7.5 \\
\hline $\mathrm{NR}^{\mathrm{c}}$ & 0.0 & 0.075 & 0.188 & 0.375 \\
\hline OD & 7.5 & 7.5 & 7.5 & 7.5 \\
\hline $\mathrm{BPO}$ & 0.8 & 0.8 & 0.8 & 0.8 \\
\hline PVA & 1.5 & 1.5 & 1.5 & 1.5 \\
\hline Water & 150 & 150 & 150 & 150 \\
\hline
\end{tabular}

a $80^{\circ} \mathrm{C}, 8$ hours, stirring rate at $200 \mathrm{rpm}, \mathrm{N}_{2}$

${ }^{\mathrm{b}} 5000 \mathrm{rpm}, 5 \mathrm{~min}$

${ }^{\mathrm{c}} M_{\mathrm{n}}$ (polydispersity index; $M_{\mathrm{w}} / M_{\mathrm{n}}$ ): 308130 (2.87), 162519

(2.19), 146001 (2.60) and 89923 (15.62)

although at the lowest content at the lowest content as shown in Figure 1b-d. It can be explained that high molecular weight NR (308 $130 \mathrm{~g} / \mathrm{mol})$ incorporated into the monomer droplets increases the internal viscosity. Therefore, it may prevent phase separation of PDVB formed during polymerization.

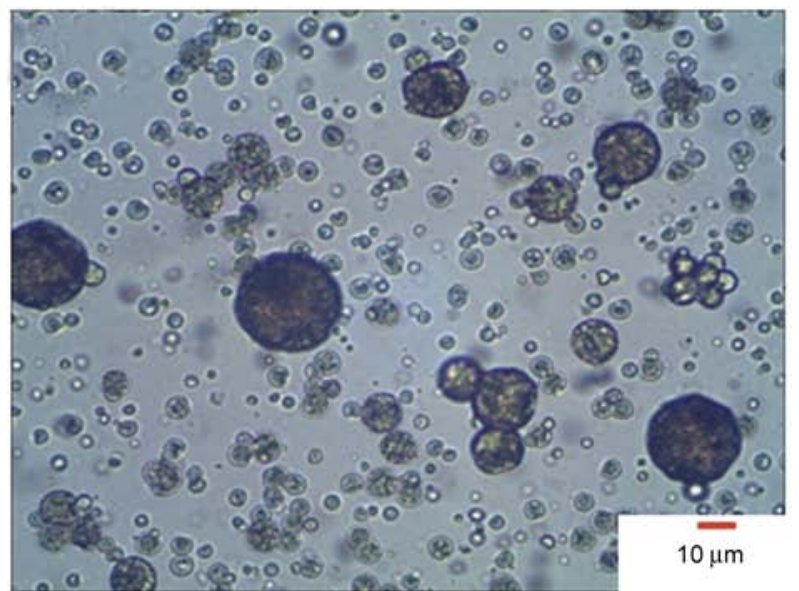

b)

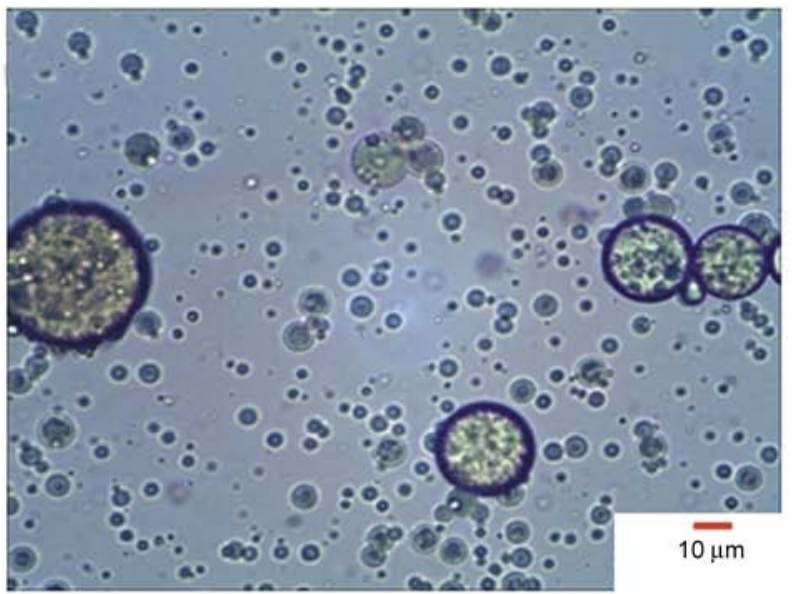

d)

Figure 1. The optical micrographs of PDVB/NR/OD particles with NR having $M_{\mathrm{n}} 308130 \mathrm{~g} / \mathrm{mol}$. NR (wt\% of DVB): (a) 0 ; (b) 1 ; (c) 2.5 and (d) 5 
To clarify this assumption, the utilization of the lower molecular weight NR was studied.

The original NR was oxidized with various amounts of aqueous hydrogen peroxide solution $(30 \% \mathrm{v} / \mathrm{v})$ in the combination with sonication for 1 hour to reduce its molecular weight. The obtained NR having different Mn measured with GPC was used for the preparation of PDVB/NR/OD capsules.

The PDVB/NR/OD capsules prepared with NR ( $1 \mathrm{wt} \%$ of DVB) having different molecular weights $\left(M_{\mathrm{n}}: 162519,146001\right.$ and $\left.89923 \mathrm{~g} / \mathrm{mol}\right)$ were shown in Figure 2. All of conditions show that the spherical particles were obtained. In the case of $162519 \mathrm{~g} / \mathrm{mol} \mathrm{NR}$ (Figure 2a), it clearly shows heterogeneous particle where PDVB/NR shell encapsulate OD core. This indicates that using the lower molecular weight NR than the original one (308 $130 \mathrm{~g} / \mathrm{mol}$; Figure 1) may reduce the internal viscosity resulting in the formation of the core-shell particles. However, when further decreased molecular weight NR (Mn: 146001 and $89923 \mathrm{~g} / \mathrm{mol}$ ) were used, the homogeneous particles were observed as shown in Figure $2 b$ and $2 c$. These phenomena may be due to their molecular weight distributions being quite high as shown in the term of polydispersity index. They are 2.52 and 15.62 for 146001 and $89923 \mathrm{~g} / \mathrm{mol}$, respectively. This means that they still have many long chains polymer which easily obstruct the phase separation. In the case of $162519 \mathrm{~g} / \mathrm{mol}$ $\mathrm{NR}$, although the $M_{\mathrm{n}}$ is higher than those of the lower ones, its molecular weight distribution is quite narrow (polydispersity index; 2.19) resulting in less long chain polymer components. This indicates that not only molecular weight of NR but also polydispersity index affect the formation of polymer capsule. However, we will discuss this phenomenon in more detail in the future. Therefore, NR having $M_{\mathrm{n}}$ about $162519 \mathrm{~g} / \mathrm{mol}$ was selected to prepare the $\mathrm{PDVB} / \mathrm{NR} / \mathrm{OD}$ capsules in the further study.

To increase NR content, the study of influence of NR weight content on the preparation of the capsule was shown in Figure 3. When low NR contents (1 and $2.5 \mathrm{wt} \%$ of DVB) were added, the spherical microcapsules were obtained as shown in Figure $3 \mathrm{~b}$ and 3c. They clearly show PDVB/NR shell encapsulating OD core. However, at higher NR content ( $5 \mathrm{wt} \%$ of DVB), the polymer chains seem to be distributed throughout the particles. These results suggested that during polymerization the present of

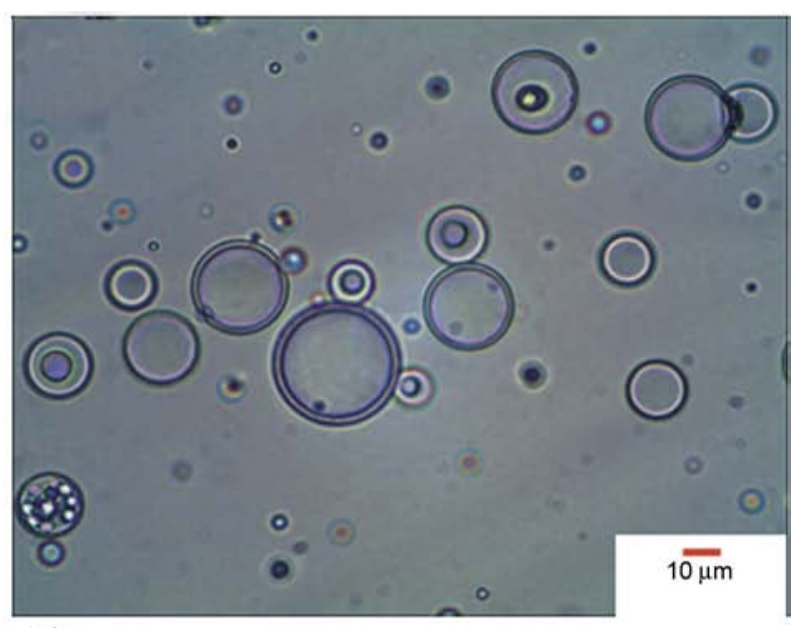

a)

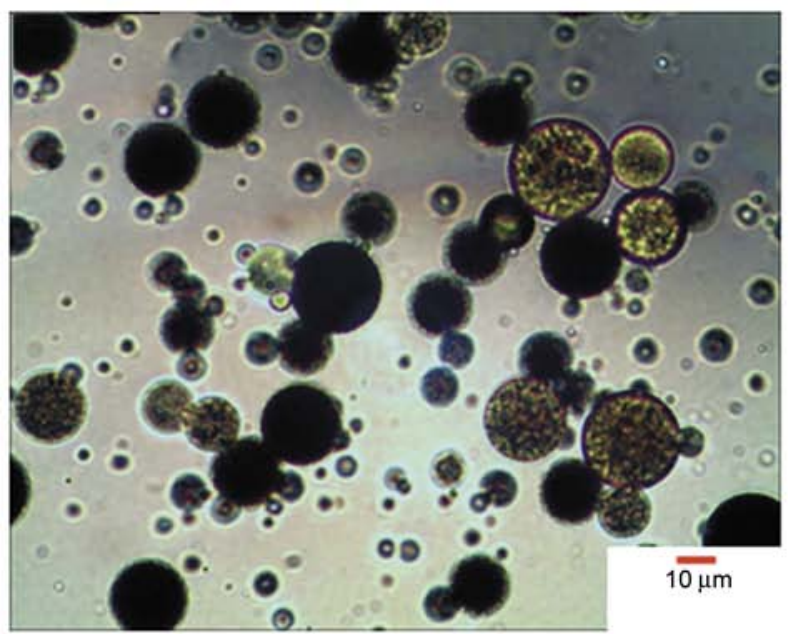

b)

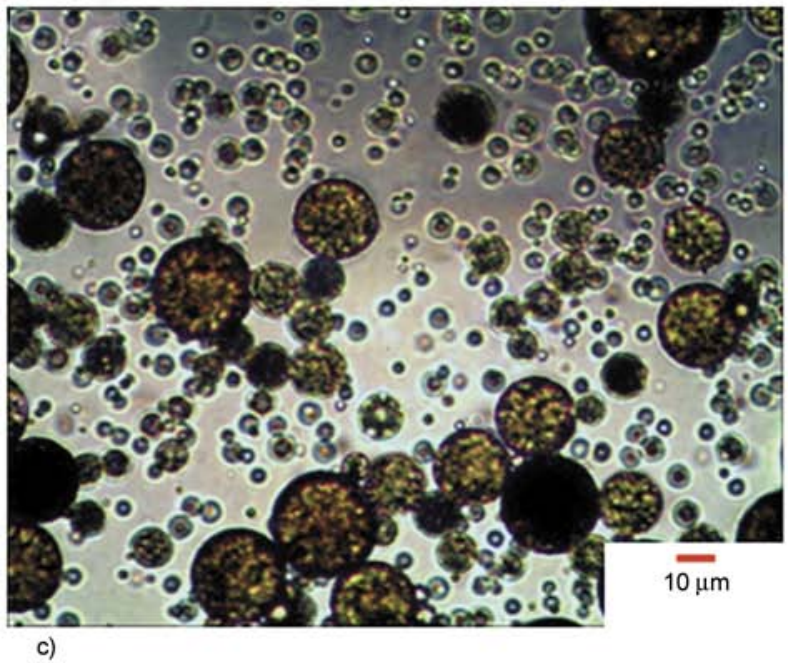

Figure 2. The optical micrographs of PDVB/NR/OD particles prepared with various molecular weight of $\mathrm{NR}$ at $1 \mathrm{wt} \%$ of DVB. $M_{\mathrm{n}}$ (polydispersity index) of NR [g/mol]: (a) 162519 (2.19); (b) 146001 (2.52) and (c) 89923 (15.62)

low concentration NR did not inhibit phase separation of PDVB chains formed in the monomer 


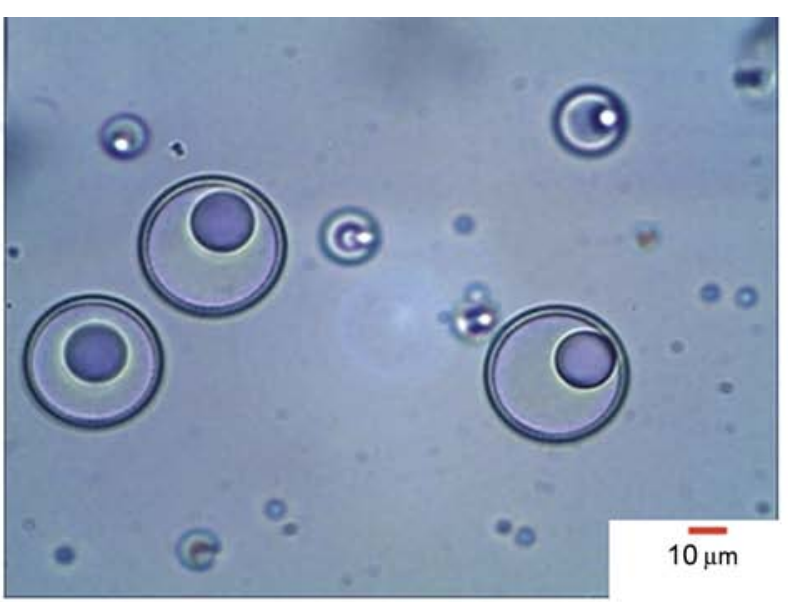

a)

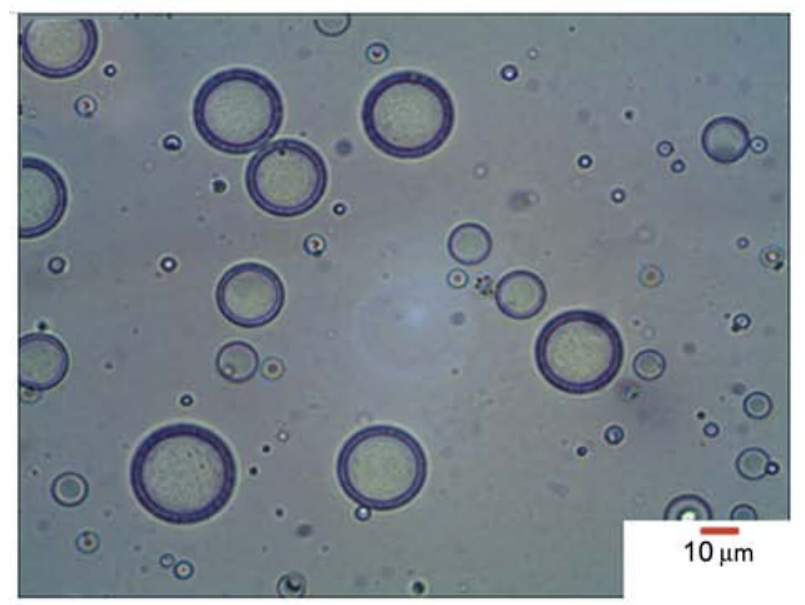

c)

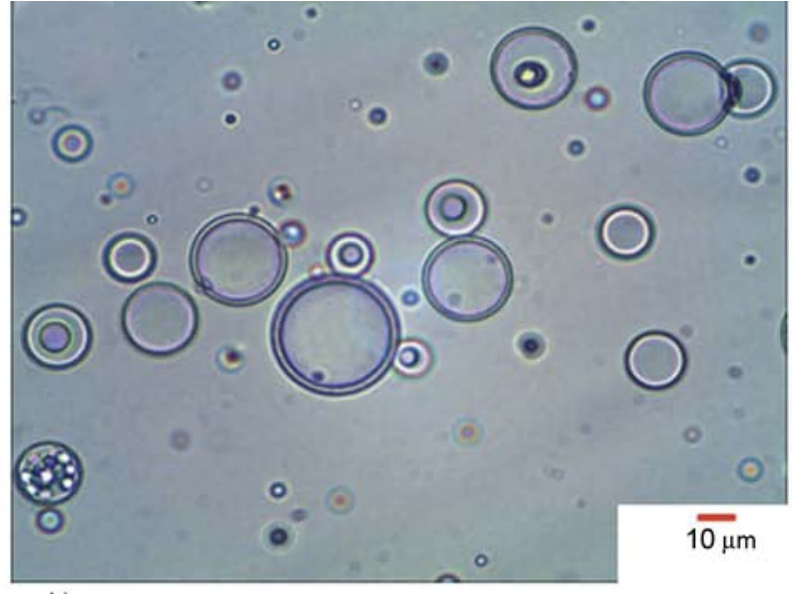

b)

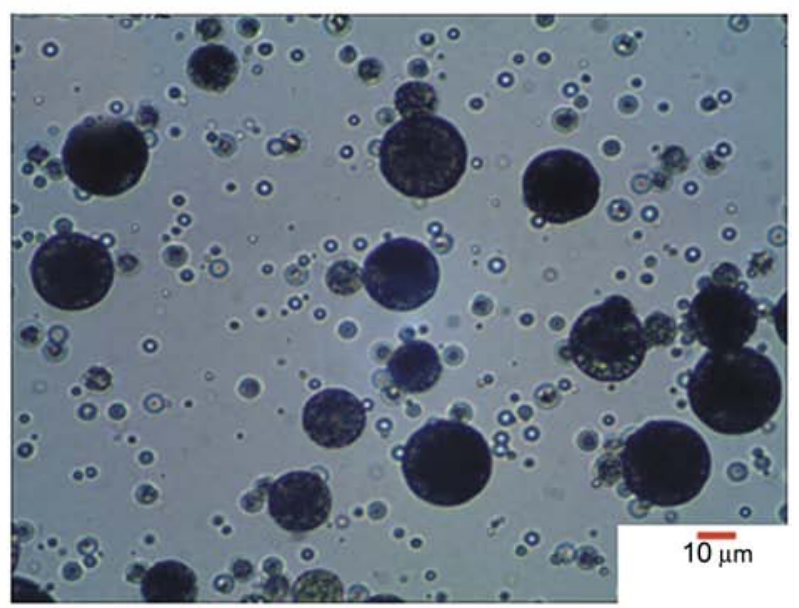

d)

Figure 3. The optical micrographs of PDVB/NR/OD particles with NR having $M_{\mathrm{n}} 162,519 \mathrm{~g} / \mathrm{mol}$. NR (wt\% of DVB): (a) 0; (b) 1 ; (c) 2.5 and (d) 5

droplets. Therefore, PDVB chains can easily diffuse to the interface and adsorb there to form the polymer shell resulting in the formation of the polymer capsule. Nevertheless, the increases of NR content until reaching a critical value ( $5 \mathrm{wt} \%$ of DVB) reduced phase separation due to high internal viscosity. In this case, the formed PDVB could not diffuse to the droplet interface resulting in homogeneous morphology particles.

The surface morphology of the capsules observed with SEM (Figure 4) support the results of OM that PDVB/OD and PDVB/NR/OD with NR $1 \mathrm{wt} \%$ of DVB have smooth outer surface of PDVB shell. No hole was observed indicating the complete encapsulation of the polymer shell. It is consistent with ultrathin cross-section TEM micrograph (Figure 5) showing the PDVB shell encapsulating OD core. In contrast, the rough outer surface of PDVB/NR/OD with NR $5 \mathrm{wt} \%$ of DVB was observed which may be due to incomplete encapsulation or less phase separation of formed PDVB chain to the outer surface. The distribution of PDVB and NR chains throughout the particles inhibit the formation of strong PDVB shell resulting in uneven surface particles.

TGA analysis showed the degradation temperature and the composition of the capsule. The degradation of PDVB/NR/OD capsule (Figure 6 curve d) consists of three steps weight loss corresponding to the decomposition of water, OD (Figure 6 curve a) and PDVB (Figure 6 curve c), respectively. In comparison with $\mathrm{OD}$, the decomposition temperature of encapsulated OD was slightly higher than that of bulk OD due to the encapsulation. The NR ( $1 \mathrm{wt} \%$ of DVB) degradation was not observed due to low content. The OD content was further used for the calculation of heat of transitions of the encapsulated OD in the following section.

The thermal properties of encapsulated OD were measured with DSC. DSC thermograms of encap- 


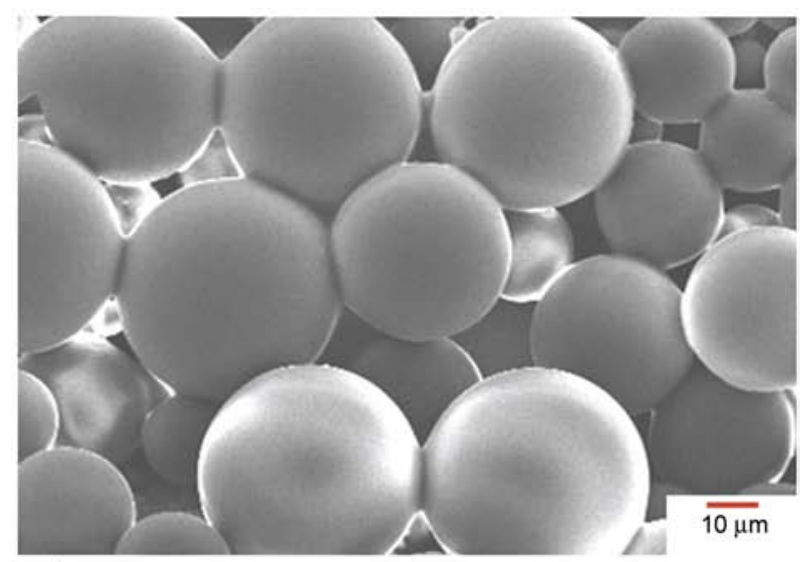

a)

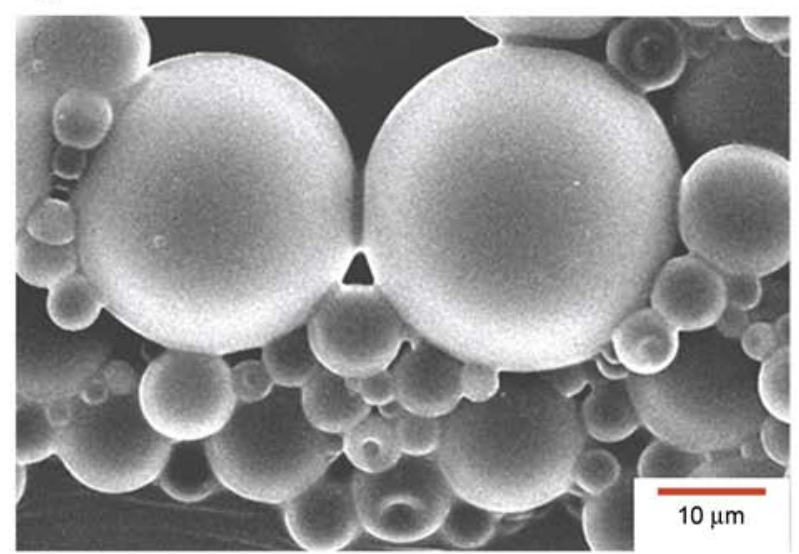

b)

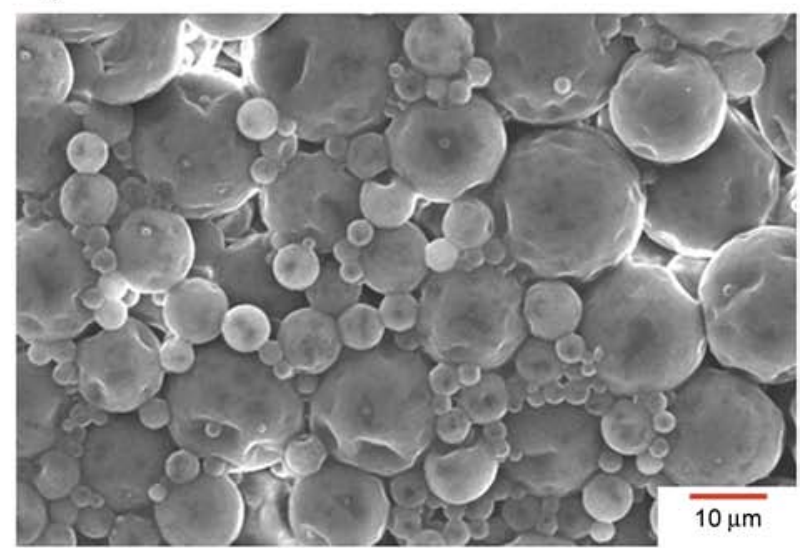

c)

Figure 4. SEM micrographs of PDVB/NR/OD particles with NR having $M_{\mathrm{n}} 162519 \mathrm{~g} / \mathrm{mol}$. NR (wt\% of DVB): (a) 0; (b) 1 and (c) 5

sulated OD in PDVB capsules (Figure 7) showed that the $H_{\mathrm{m}}(153.0 \mathrm{~J} / \mathrm{g}-\mathrm{OD})$ and $H_{\mathrm{c}}(151.8 \mathrm{~J} / \mathrm{g}-\mathrm{OD})$ of encapsulated OD were lower than those of the bulk OD (241.7 and $247.0 \mathrm{~J} / \mathrm{g}$ of $H_{\mathrm{m}}^{0}$ and $H_{\mathrm{c}}^{0}$, respectively). This phenomenon is quite general for the encapsulation as also observed by other researchers $[3,5,6,9-11,15-19]$. The possible reason of the reduction of $H_{\mathrm{m}}$ and $H_{\mathrm{c}}$ of encapsulated heat storage materials is that the phase separation between the

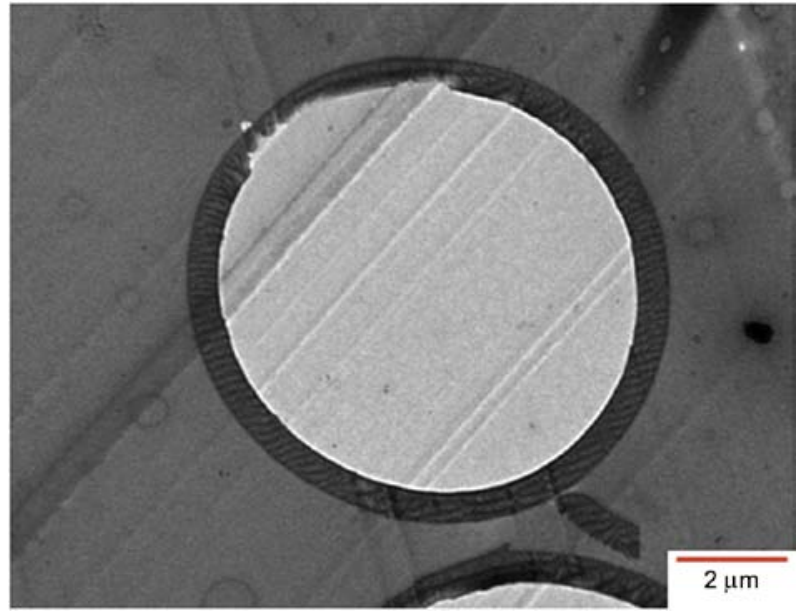

Figure 5. TEM micrographs of cross sections of PDVB/OD capsule

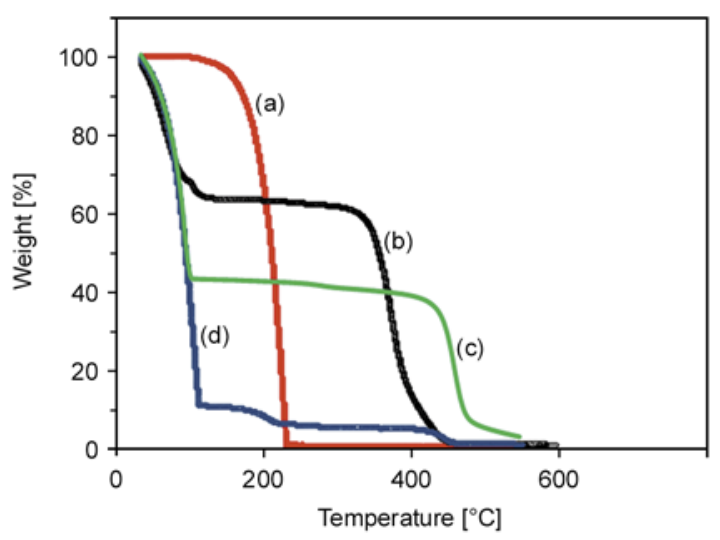

Figure 6. TGA thermograms of (a) bulk OD, (b) NR latex, (c) PDVB and (d) PDVB/NR/OD capsule (1 wt $\%$ of DVB) measured at the heating rate of $5^{\circ} \mathrm{C} / \mathrm{min}$

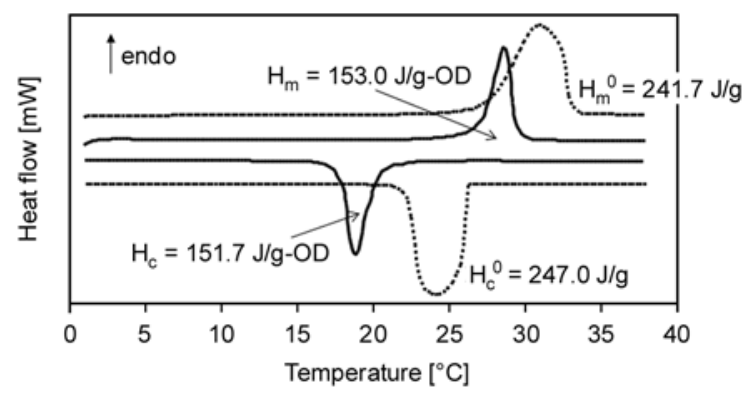

Figure 7. DSC thermograms of bulk OD (dot line) and encapsulated OD (solid line) in PDVB particles measured at the scanning rate of $5^{\circ} \mathrm{C} / \mathrm{min}$

polymer shell and heat storage material core was incomplete as in the case of PDVB/HD microcapsules prepared by suspension polymerization [11]. Moreover, the capsules may have some unreacted monomers or oligomers incorporated at the interface between polymer shell and heat storage material core as in the case of PS/HD microcapsules pre- 
pared by suspension polymerization [16]. They may act as a compatibilizer and increase the miscibility between polymer and heat storage material leading to the decrease of their phase separation in the monomer droplet. However, to overcome this problem, the copolymerization with more polar monomers is a good idea as copolymerization of PDVB with methyl acrylate, ethyl acrylate and butyl acrylate [11]. In the case of phase transition temperature, $T_{\mathrm{m}}$ of encapsulated OD $\left(28.3^{\circ} \mathrm{C}\right)$ was almost the same as that of bulk OD $\left(30.0^{\circ} \mathrm{C}\right)$. In contrast, $T_{\mathrm{c}}$ was shifted to lower temperature compared to bulk OD. This phenomenon is called supercooling. Supercooling leads to the reduction of $T_{\mathrm{c}}$ resulting in a release of latent heat at a lower temperature or over a wider temperature range. This effect may limit the applications. To prevent supercooling, nucleating agents were incorporated in the heat storage materials core during the encapsulation process. However, increasing nucleating agent content decreased the latent heat $[20,21]$. At the present, there is still no good solution to overcome this problem.

In the case of PDVB/NR capsules, the thermal properties of encapsulated OD were similar as those of OD in PDVB capsule. $H_{\mathrm{m}}$ and $H_{\mathrm{c}}$ of encapsulated OD were much lower than those of the bulk ones while a slightly lower than those of OD in PDVB capsule. It may be due to the presence of NR in OD matrix at the interface of capsule shell and OD core reduces the crystallization of the encapsulated ones. However, in the case of homogeneous particle, the increase of NR weight percent up to 5 showed greatly decreasing of heat of transition of the OD (Table 2). It may be due to the distribution of NR

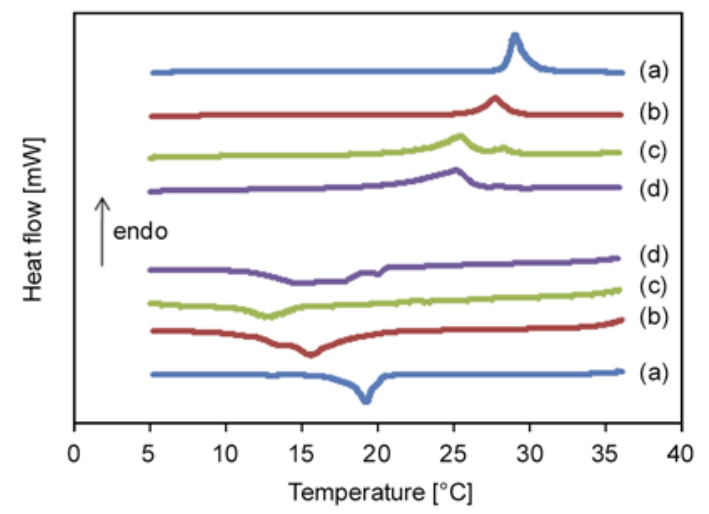

Figure 8. DSC thermograms of the encapsulated OD in $\mathrm{PDVB} / \mathrm{NR}$ capsule measured at the scanning rate of $5^{\circ} \mathrm{C} / \mathrm{min}$. NR (wt $\%$ of DVB): (a) 0 ; (b) 1 ; (c) 2.5 and (d) 5
Table 2. Thermal properties of encapsulated OD in PDVB/ NR capsule prepared with various weight percents of NR

\begin{tabular}{|c|c|c|}
\hline \multirow{2}{*}{ NR (wt\% of DVB) } & \multicolumn{2}{|c|}{ Heat of transition (J/g-OD) } \\
\cline { 2 - 3 } & $\mathbf{H}_{\mathbf{c}}$ & $\mathbf{H}_{\mathbf{m}}$ \\
\hline 0 & 151.7 & 153.1 \\
\hline 1 & 124.2 & 129.1 \\
\hline 2.5 & 126.3 & 124.7 \\
\hline 5 & 106.7 & 114.5 \\
\hline
\end{tabular}

and PDVB, which restricts the crystallization of OD. $T_{\mathrm{m}}$ of the encapsulated OD was almost the same as that of the bulk ones while $T_{\mathrm{c}}$ was also shifted to the lower temperature compared to bulk OD (Figure 8). However, due to their high total surface area compared to bulk OD, these PDVB/NR/OD capsules are quite acceptable for energy storage applications even having a slightly lower latent heat.

\section{Conclusions}

The microcapsule of PDVB/NR encapsulating OD was successfully prepared by suspension polymerization utilizing the SaPSeP method. Using high molecular weight NR, the capsule could not be formed even though at $1 \mathrm{wt} \%$ of DVB. This is due to the presence of NR in the monomer droplet increasing the internal viscosity which prevents phase separation of PDVB formed during polymerization. However, the reduction of NR molecular weight leads to the formation of polymer capsule at the appropriate NR content. It was also found that the increase of NR content gradually reduced phase separation of PDVB due to the increase of internal viscosity. Therefore, it can be concluded that both molecular weight and content of NR are important factors affected on the preparation of PDVB/NR/ OD capsule. The thermal properties of encapsulated OD in the PDVB/NR capsule were lower than those of bulk as in the case of PDVB capsule.

\section{Acknowledgements}

This work was supported by The National Research Council, Thailand (No. 44703).

\section{References}

[1] Su J-F., Wang L-X., Ren L.: Preparation and characterization of double-MF shell microPCMs used in building materials. Journal of Applied Polymer Science, 97, 1755-1762 (2005).

DOI: $10.1002 / a p p .21205$ 
[2] Peng S., Fuchs A., Wirtz R. A.: Polymeric phase change composites for thermal energy storage. Journal of Applied Polymer Science, 93, 1240-1251 (2004). DOI: $10.1002 /$ app.20578

[3] Cho J-S., Kwon A., Cho C-G.: Microencapsulation of octadecane as a phase-change material by interfacial polymerization in an emulsion system. Colloid and Polymer Science 280, 260-266 (2002).

DOI: $10.1007 / \mathrm{s} 00396-001-0603-\mathrm{X}$

[4] Farid M. M., Khudhair A. M., Razack S. A. K., AlHallaj S.: A review on phase change energy storage: Materials and applications. Energy Conversion and Management, 45, 1597-1615 (2004).

DOI: 10.1016/j.enconman.2003.09.015

[5] Zhang X. X., Fan Y. F., Tao X. M., Yick K. L.: Fabrication and properties of microcapsules and nanocapsules containing $n$-octadecane. Materials Chemistry and Physics, 88, 300-307 (2004).

DOI: 10.1016/j.matchemphys.2004.06.043

[6] Zhang H., Wang X.: Fabrication and performances of microencapsulated phase change materials based on $n$ octadecane core and resorcinol-modified melamineformaldehyde shell. Colloids and Surfaces A: Physicochemical and Engineering Aspects, 332, 129-138 (2009).

DOI: 10.1016/j.colsurfa.2008.09.013

[7] Onder E., Sarier N., Cimen E.: Encapsulation of phase change materials by complex coacervation to improve thermal performances of woven fabrics. Thermochimica Acta, 467, 63-72 (2008).

DOI: $10.1016 /$ j.tca.2007.11.007

[8] Sánchez P., Sánchez-Fernandez M. V., Romero A., Rodríguez J. F., Sánchez-Silva L.: Development of thermo-regulating textiles using paraffin wax microcapsules. Thermochimica Acta, 498, 16-21 (2010). DOI: $10.1016 /$ j.tca.2009.09.005

[9] Chaiyasat P., Suzuki T., Minami H., Okubo M.: Thermal properties of hexadecane encapsulated in poly (divinylbenzene) particles. Journal of Applied Polymer Science, 112, 3257-3266 (2009).

DOI: $10.1002 /$ app. 29648

[10] Chaiyasat P., Ogino Y., Suzuki T., Okubo M.: Influence of water domain formed in hexadecane core inside cross-linked capsule particle on thermal properties for heat storage application. Colloid and Polymer Science, 286, 753-759 (2008).

DOI: $10.1007 / \mathrm{s} 00396-007-1831-5$

[11] Chaiyasat P., Ogino Y., Suzuki T., Minami H., Okubo M.: Preparation of divinylbenzene copolymer particles with encapsulated hexadecane for heat storage application. Colloid and Polymer Science, 286, 217-223 (2008).

DOI: $10.1007 / \mathrm{s} 00396-007-1764-\mathrm{Z}$
[12] Ogino Y., Suzuki T., Okubo M.: Preparation of poly (divinylbenzene) particles with encapsulated hexadecane for heat storage application (in Japanese). Kobunshi Ronbunshu, 64, 171-176 (2007).

DOI: $10.1295 /$ koron.64.171

[13] Chaiyasat P., Chaiyasat A., Boontung W., Promdsorn S., Thipsit S.: Preparation and characterization of poly(divinylbenzene) microcapsules containing octadecane. Materials Science and Applications, 2, 10071013 (2011).

DOI: $10.4236 / \mathrm{msa} .2011 .28136$

[14] de Oliveira P. C., de Oliveira A. M., Garcia A., de Souza Barboza J. C., de Carvalho Zavaglia C. A., dos Santos A. M.: Modification of natural rubber: A study by ${ }^{1} \mathrm{H}$ NMR to assess the degree of graftization of polyDMAEMA or polyMMA onto rubber particles under latex form in the presence of a redox couple initiator. European Polymer Journal, 41, 1883-1892 (2005). DOI: $10.1016 /$ j.eurpolymj.2005.02.030

[15] Zhang X-X., Tao X-M., Yick K-L., Wang X.: Structure and thermal stability of microencapsulated phasechange materials. Colloid and Polymer Science, 282, 330-336 (2004). DOI: $10.1007 / \mathrm{s} 00396-003-0925-\mathrm{y}$

[16] Ai Y., Jin Y., Sun J., Wei D.: Microencapsulation of nhexadecane as phase change material by suspension polymerization. e-Polymers, no. 098 (2007).

[17] Sarı A., Alkan C., Karaipekli A., Uzun O.: Microencapsulated $n$-octacosane as phase change material for thermal energy storage. Solar Energy, 83, 1757-1763 (2009).

DOI: $10.1016 /$ j.solener.2009.05.008

[18] Sarı A., Alkan C., Karaipekli A.: Preparation, characterization and thermal properties of PMMA $/ n$-heptadecane microcapsules as novel solid-liquid microPCM for thermal energy storage. Applied Energy, 87, 15291534 (2010). DOI: 10.1016/j.apenergy.2009.10.011

[19] Zhang H., Wang X.: Synthesis and properties of microencapsulated $n$-octadecane with polyurea shells containing different soft segments for heat energy storage and thermal regulation. Solar Energy Materials and Solar Cells, 93, 1366-1376 (2009).

DOI: $10.1016 /$ j.solmat.2009.02.021

[20] Zhang X-X., Fan Y-F., Tao X-M., Yick K-L.: Crystallization and prevention of supercooling of microencapsulated $n$-alkanes. Journal of Colloid and Interface Science, 281, 299-306 (2005).

DOI: $10.1016 /$ j.jcis.2004.08.046

[21] Fan Y. F., Zhang X. X., Wang X. C., Li J., Zhu Q. B.: Super-cooling prevention of microencapsulated phase change material. Thermochimica Acta, 413, 1-6 (2004). DOI: $10.1016 /$ j.tca.2003.11.006 